\title{
DIVERSIFICAÇÃO DAS GRANDES \\ EMPRESAS E GRUPOS EMPRESARIAIS BRASILEIROS: ALGUNS \\ APONTAMENTOS
}

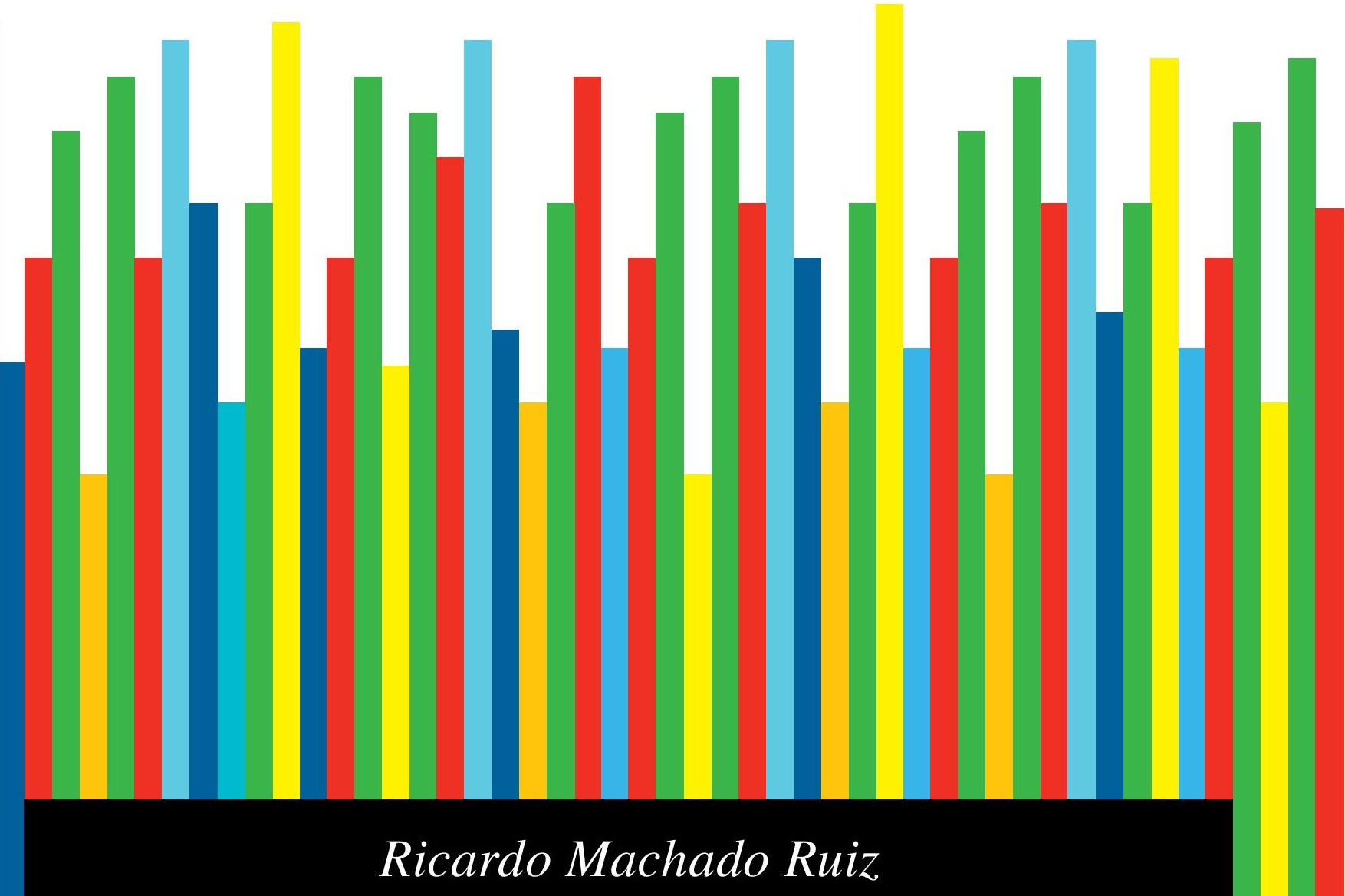


RESUMO

A diversificação dos grandes grupos e empresas é condicionada pela sua coerência ou coesão corporativa e requer ambientes políticos e econômicos que reduzam a incerteza e favoreçam investimentos que ousem ir além do core business da firma. Na ausência desse ambiente, a estratégia dos capitais nacionais tem se mostrado conservadora e especializante, em particular em setores intensivos em tecnologia. Recentemente se observam algumas diversificações induzidas pelo crescimento interno e apoiadas por políticas públicas. Entretanto, a ausência de um núcleo endógeno de inovação e uma modesta escala financeira colocam em dúvida seu êxito em um ambiente de abertura econômica.

Palavras-chave: diversificação, inovação, coesão, corporações, especialização.

\section{ABSTRACT}

Diversification of large companies and groups is contingent on their corporate coherence or cohesion. Diversification entails political and economic environments which lessen uncertainty and favor investments daring to go beyond the core business of the company. When such environment is missing, the strategy of the national capital has proven to be specializing and conservative, mainly when concerning intensive technology sectors. We have recently observed some diversification driven by internal growth and supported by public policies. However, doubts can be raised as to its success in an environment of economic overture, as it lacks an endogenous innovation nucleus and because of its modest financial scale.

Keywords: diversification, innovation, cohesion, corporations, specialization. 


\section{COERÊNCIA E DIVERSIFICAÇÃO}

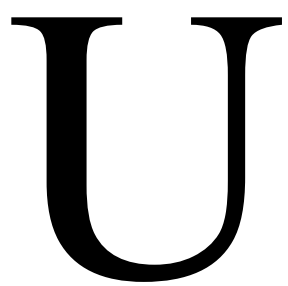

ma avaliação da diversificação das grandes empresas e dos grupos empresariais é também um estudo dos investimentos e das estratégias de negócios. Quando se fala em investimento, a referência é o crescimento dos ativos, entretanto, quando o foco são investimentos para diversificação, temos negócios e riscos empresariais que merecem ser considerados com peculiar atenção. Para matizar essas diferenças, seguem algumas rápidas notas teóricas.

Dentre as muitas perspectivas teóricas da firma, a "visão baseada em recursos", a teoria "capacitações centrais" ou da "coerência corporativa" são as mais adequadas para pensar a organização e estratégia de grandes empresas e grupos econômicos. O argumento central é de que a firma é um conjunto articulado e heterogêneo de recursos e de serviços gerenciais capazes de gerar rendas líquidas de forma específica e singular, não sendo possível sua reprodução imediata ${ }^{1}$.

A firma, como um "arranjo histórico de recursos", tem específicas vantagens competitivas em determinados ambientes concorrenciais. Suas bases produtivas e áreas comerciais definem e limitam o horizonte de crescimento e de diversificação. Investimentos distantes dessas áreas de especialização tendem a ser mais arriscados. A união e, principalmente, a intersecção das bases produtivas e das áreas comerciais formam uma área de especialização e um centro de competências, uma característica marcante das grandes corporações (grandes empresas ou grupos) ${ }^{2}$.

As restrições ao crescimento e à diversificação da firma dependem, portanto, da sua capacidade de replicar, inovar e gerenciar ativos nessas áreas de especialização. Essa capacidade tende a ser decrescente quanto mais distante estiver o investimento dos core business das grandes firmas multiprodutoras e grupos econômicos (Prahalad \& Hamel, 1990; Dosi, Teece \& Winter, 1992).
Essas referências teóricas já permitem uma diferenciação entre os investimentos para o crescimento e para a diversificação. Os investimentos que configuram somente crescimento reafirmam uma posição por meio do aumento do estoque de ativos produtivos desses core business. Ou seja, esses investimentos ampliam e consolidam posições que as empresas já possuem e reafirmam suas capacitações.

Quanto aos investimentos que diversificam a base tecnológica e as áreas de mercado, esses modificam a escala do capital e - principalmente - seu escopo. Novos modos de produção, produtos, clientes, distribuidores e fornecedores são somados à antiga estrutura produtiva do grupo/empresa. Logo, a diversificação tem contornos mais ousados e arriscados. É uma inovação para a firma: é fazer algo que não se produzia e concorrer onde não se concorria.

$\mathrm{O}$ ato de investir já carrega um nível de incerteza elevado: não há garantias sobre os cálculos prospectivos de receitas, custos e lucros e há grande irreversibilidade na decisão empresarial (sunk costs). Em uma economia de mercado com decisões privadas, não é possível coordenar, antever e computar ações de múltiplos capitais, o que leva à busca de "variadas garantias" para minimizar os riscos dos negócios. Quando o investimento ocorre em novos mercados com a adição de novos produtos ou processos, o risco privado cresce significativamente, pois uma parte importante do conhecimento que baliza cálculos de rentabilidade e estratégias passa a ser de pouca valia em outro ambiente concorrencial ${ }^{3}$.

Estas notas são fundamentais para matizar e compreender os requisitos econômicos e políticos necessários para uma ampla e intensa diversificação dos capitais privados. Como se notará, tais requisitos são mais complexos e difíceis que os investimentos voltados para a ampliação de ativos correntes.

\section{ILUSTRAÇÕES HISTÓRICAS}

Na industrialização brasileira um importante movimento de diversificação empre-

\section{RICARDO} MACHADO RUIZ

é professor da Faculdade de Ciências Econômicas e do Centro de Desenvolvimento e Planejamento Regional (Cedeplar), ambos da Universidade Federal de Minas Gerais.

1 Importantes referências teóricas são: Penrose (1959) eChandler (1962, 1977 e 1990). Outrasreferênciassão Foss (1997; 1998), Teece et al. (1994), Teece (1993; 1996), Prahalad \& Hamel (1990), Dosi, Teece \&Winter (1992) Dosi, Faillo\&Marengo (2003).

2 Outras interpretações da firma podem ser encontradas em: Alchian \& Demsetz (1972), Hart \& Moore (1990), Holmstrom \& Milgrom (1994), Holmstron \& Tirole (1989), Williamson (1989). Nesses textos temos referências variadas que sinalizam a expansão da firma como condicionada pela organização interna, pelas trocas de mercado e pelos seus sistemas de incentivos.

3 Rumelt (1984, p. 139) comenta esse ponto: "Which activities should an entrepreneurcombine? The ge neral answer is, those that will exhibit stronglydependentpostentry efficiencies. Given a bundle of activities with total postentry efficiency determined by a random variable $X$, adding new activities that involved sunk costscan neverbepro- 
fitable if their efficiencies are uncorrelated with $X$. Thus new activities are added until thepoint wherefurther additions would not add sufficiently large expected profits orprofit variance to justify the added sunk cost".

4 As conexões entre os capitais industrial e cafeeiro não foram lineares. Saes (1989) apresenta uma interessante organização e vários comentários sobre o debate da industrialização brasileira onde estão pontuadas essas relações de complementariedade e de oposição. sarial ocorreu na articulação do complexo cafeeiro com a indústria. A metamorfose e articulação dos grandes "coronéis do café" em "capitães da indústria" é hoje um tema conhecido: grandes plantadores de café se tornaram proprietários de firmas industriais e comerciais, de empresas de serviços de transporte, de bancos comerciais e de tradings. Quando não investiram nas manufaturas, os cafeicultores tinham nelas sua oferta de serviços e de insumos. Nessas relações econômicas foram construídas conexões e composições variadas entre os capitais cafeeiro e industrial ${ }^{4}$.

Observando alguns grandes grupos nacionais que surgiram no início do século, Reiss (1980, 1983) considera-os "empórios industriais". Avalia que, de modo geral, os grandes capitais tiveram um amplo leque de atividades: industriais, comerciais, agrícolas e financeiras. Afirma que, na sua origem, os grupos industriais nacionais foram marcados por um restrito grau de coerência industrial e formaram estruturas conglomeradas, porosas e heterogêneas.

Um clássico exemplo de "empório industrial" é o grupo Matarazzo. A origem do grupo Matarazzo encontra-se no ano de 1882, em uma empresa comercial em Sorocaba, centro de negócios da época. Até 1930, o grupo manteve-se nas áreas comerciais, agropecuárias e em alguma atividade manufatureira. No início de 1970, o grupo tinha empresas dispersas em vários setores: alimentos, papel e celulose, cimento, têxtil, química, etc. Esse conjunto de empresas tinha pouca ou nenhuma sinergia tecnológica e organizacional ou mesmo identidade corporativa; era quase um portfólio de negócios (Reiss, 1980; Queiroz, 1972).

Um maior grau de coerência empresarial e industrial só foi alcançado na industrialização produtora de bens de consumo duráveis, bens de capital e insumos básicos. Nesse contexto de larga e mais complexa recomposição setorial da economia, a diversificação dos capitais nacionais só foi possível com o suporte do Estado, seja por meio do apoio de empresas estatais, de bancos públicos e/ou de políticas que restringiam ou regulavam a participação do capital estrangeiro (exemplo: autopeças, alumínio, mineração, siderúrgica, etc.). Foram utilizadas variadas isenções fiscais, financiamentos e políticas de compras públicas para diferenciar as taxas de rentabilidade em favor de produtores domésticos, sejam eles de capitais nacionais ou estrangeiros.

Por exemplo, o grupo Villares tem sua origem no ano de 1918 com a comercialização de manufaturas de ferro e aço. Em 1922, com uma pequena metalurgia, a empresa passa a produzir e montar elevadores. Em 1942, é criada a Elevadores Atlas S. A., e dois anos depois foi fundada a Aços Villares. Em 1952, foi fundada a VICSA, fábrica de anéis para pistão. No ano de 1953, foi constituída a Equipamentos Industriais Villares, para fabricar pontes rolantes e outros equipamentos (Queiroz, 1972).

As origens do grupo Votorantim se encontram em 1918, com a fábrica de tecidos Votorantim. Em 1936 é iniciada a produção de cimento; quarta fábrica de cimento no Brasil. No ano de 1937, associando-se à empresa americana Tubize Chatillon Hopewell, o grupo funda a Nitro Química, empresa produtora de raiom. No mesmo ano, entra em operação a Siderúrgica Barra Mansa. Em 1941, inicia-se a construção da CBA (Cia. Brasileira de Alumínio). Durante a década 1950, seguindo o crescimento do setor de insumos básicos, expande as atividades no setor cimenteiro e metalúrgico e, em 1967, passa a produzir zinco com a Cia. Mineira de Metais (Reiss, 1980).

O grupo Klabin iniciou as atividades em 1899, mas foi em 1906 que fundou sua primeira fábrica de papel. Em 1934, as atividades papeleiras ganharam destaque. Nessa data foi fundada a Indústria Klabin do Paraná de Celulose. Em 1941 inicia-se a implantação de um conjunto industrial para produção de celulose, pasta mecânica e papel de jornal, até então importado. No ano de 1958, com os estímulos do Plano de Metas, iniciou sua primeira expansão: instalou uma fábrica de celulose kraft natural e branqueada. 


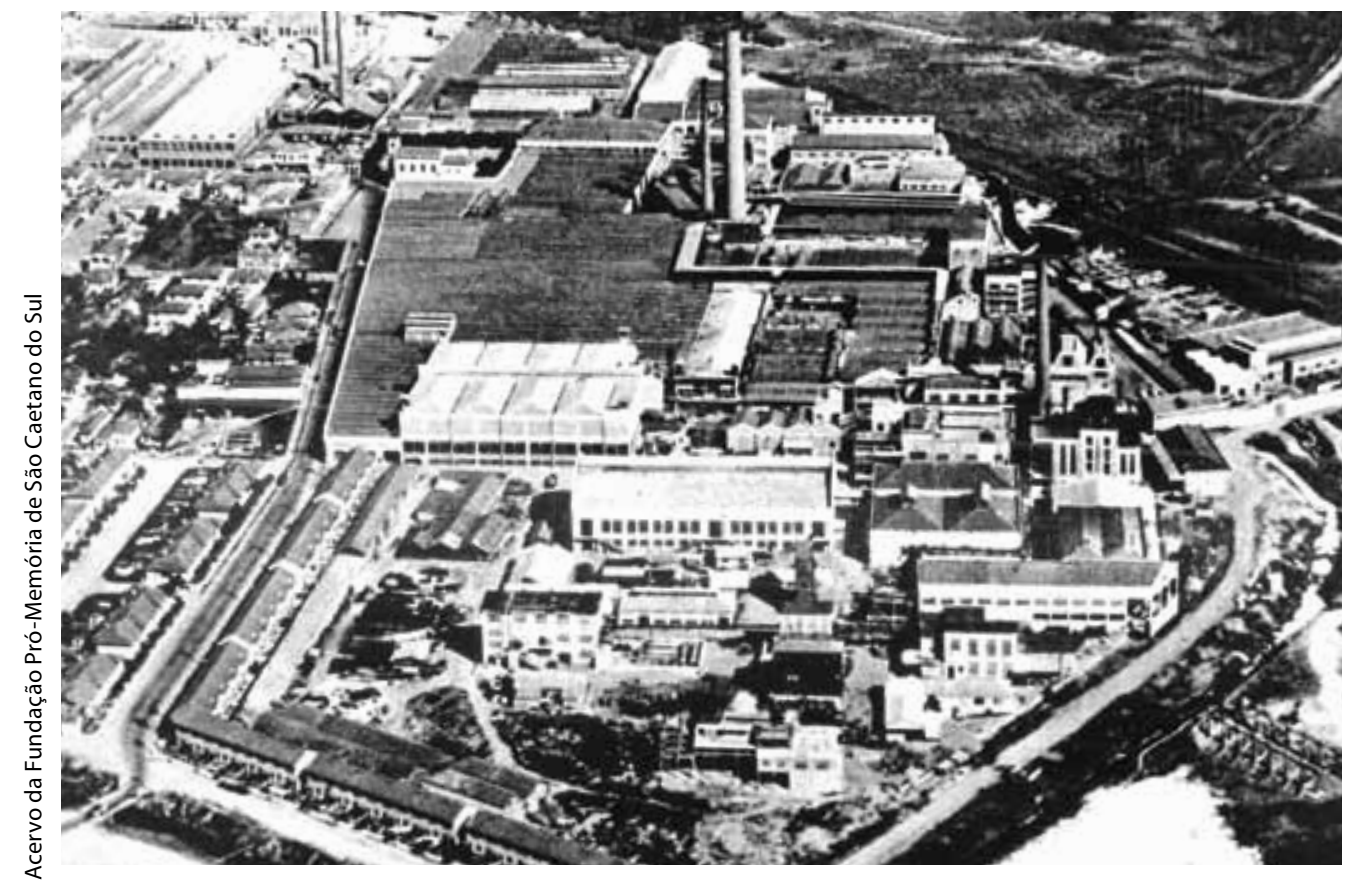

A empresa Sadia tem sua origem em 1944 como um pequeno frigorífico de abate de aves e suínos e moinho de trigo na cidade de Concórdia, em Santa Catarina. A expansão deu-se incorporando pequenos frigoríficos, verticalizando a produção e controlando o fornecimento de matéria-prima e a distribuição. No ano de 1953, cria o moinho da Lapa e, em 1961, funda a Cia. Brasileira de Frigoríficos (Frigobrás), ambos na cidade de São Paulo (Aquino, 1991).

Outras empresas e corporações surgiram como fornecedores de grandes demandas de empresas estrangeiras, nacionais e estatais que moldavam a indústria. Pode-se citar Metal Leve, Cofap, Weg, Tupy, Hering, Gerdau, Perdigão, Suzano, Ultra, Ipiranga, Brahma, Alpargatas como outros grupos privados que cresceram e se diversificaram durante o longo período de substituição de importações ${ }^{5}$.

\section{INSTABILIDADE COM REFORÇO DA COESÃO: AS ESTRATÉGIAS NA DÉCADA DE 1980 ${ }^{6}$}

Com a exaustão do modelo de substituição de importações juntamente com a crise da dívida externa no início da década de 1980 , as estratégias de crescimento com diversificação no mercado interno se enfraquecem. As restrições às importações, as políticas setoriais e a escassez de divisas mantiveram o mercado interno "fechado" à oferta externa de produtos, mas a instabilidade macroeconômica minou a expansão no mercado interno.

A incerteza em diversos fronts levou as grandes empresas à aquisição de firmas e ativos que funcionaram como reserva de valor, um modo de preservar riqueza frente às instabilidades do valor da moeda e risco associados a potenciais intervenções do Estado. Contudo, poucos grupos foram guiados por uma estratégia especulativa e patrimonialista. A larga maioria dos grupos e empresas se manteve na sua tradicional área de expansão ou especialização construída na industrialização.

As estratégias dominantes das corporações foram as de controle dos mercados internos. O reforço da posição competitiva por meio da aquisição de concorrentes (estratégia horizontal) foi dominante, e poucos grupos diversificaram sua inserção setorial, mas, quando o fizeram, o mercado-alvo foi o externo. Não obstante o viés da política econômica para inserções no mercado externo, o peso do mercado interno dominou. Para a grande maioria das corporações, o mercado externo era ainda

\section{Vista aérea das instalações do antigo grupo Matarazzo}

5 Ver Aquino $(1987,1991)$ para mais informações sobre a origem deoutrosgruposeconômicos.

6 Esse item tem como referência Ruiz (1994) e os relatórios de pesquisa do estudo da Unicamp (1996). 
muito competitivo e largamente desconhecido.

A diversificação para setores industriais intensivos em tecnologia foi estimulada por políticas públicas variadas, tais como políticas de compra governamental, reservas de mercado e proteção às importações. Grupos se diversificaram para esses setores, inclusive grupos financeiros de grande porte, mas poucos sustentaram uma estratégia centrada exclusivamente nas oportunidades tecnológicas. A maioria das estratégias não evoluiu a ponto de terem nesses setores uma parte importante da estrutura dos grupos e grandes empresas.

Em síntese, durante a década de 1980, os grupos e as grandes empresas afirmaram suas clássicas inserções setoriais que foram complementadas com modestas diversificações sinérgicas. Secundariamente iniciaram uma inserção no mercado externo e, eventualmente, entraram em novos setores intensivos em tecnologia e apoiados por políticas públicas. Para muitos grupos, as estratégias mais cautelosas determinaram um bom desempenho em um período de incertezas e instabilidade. Comparativamente à vigorosa diversificação nas décadas anteriores, o cenário da década de 1980 pode ser considerado como conservador.

\section{AJUSTES E ESTRATÉGIAS NA DÉCADA DE 1990}

Na primeira metade da década de 1990 as estratégias ganham um perfil ainda mais conservador e, em vários casos, regressivos. As especializações setoriais se generalizam e a opção geral foi de redução do grau de diversificação das estruturas empresariais. Em alguns casos, as estratégias foram acompanhadas de especializações intrassetoriais que levaram ao empobrecimento do leque de produtos ofertados e à dependência do fornecimento de insumos e partes críticas.

$\mathrm{Na}$ organização intrafirma o ajuste recessivo levou a desverticalizações e reorganizações administrativas em larga escala. A reengenharia, a produção enxuta, a terceirização, o downsizing se tornaram termos comuns que refletiam uma modernização corporativa mesclada com ajustes defensivos (Ruiz, 1994; Unicamp, 1996; Canuto, 1997).

A recessão e a abertura comercial estimularam especializações setoriais e intrassetoriais que procuraram preservar as posições mais competitivas no mercado interno. Em alguns casos, o conhecimento sobre a demanda interna, a necessidade da customização e os serviços pós-venda funcionaram como barreira à entrada de produtores externos; entretanto, essa barreira foi progressivamente corroída com a persistência e adequação da oferta externa à demanda interna.

Para aqueles grupos e grandes empresas com alguma competitividade externa, o drive exportador passou a ser uma saída para o crescimento, uma vez que não se visualiza uma rápida recuperação da demanda. Entretanto, poucos grupos foram capazes de crescer por meio das exportações, e o mercado interno se manteve como a base de acumulação de capital.

Com o abandono das políticas setoriais, fim de preferência nas compras públicas, e com a manutenção da abertura comercial, as diversificações em indústrias intensivas em tecnologia foram praticamente abandonadas. As incursões nos novos setores industriais foram preteridas em relação àqueles setores mais "maduros" baseados em vantagens naturais ou com forte componente non-tradable (Ruiz, 1994; Unicamp, 1996).

A estabilização inflacionária produzida pelo Plano Real foi, com certeza, um requisito para um novo movimento de diversificação, mas não foi suficiente. Para que tal movimento ocorresse, seriam necessárias outras políticas pró-investimento com forte regulação setorial, pelo menos esta era a experiência histórica dos grupos quando chamados à diversificação. Os choques externos, em geral relacionados aos fluxos de capitais, impediram um crescimento sustentado.

$\mathrm{Na}$ ausência desse ambiente institucional, a ampla e intensa abertura comercial aliada à valorização cambial, a falta de políticas preferenciais, a demanda interna disputada por concorrentes externos e as restrições ao 
crédito interno mantiveram dominantes as estratégias corporativas defensivas e a especialização setorial e intrassetorial.

Para alguns grandes capitais nacionais a década de 1990 só não correspondeu a um "congelamento das estruturas" devido às privatizações. Para um número seleto de corporações nacionais, as empresas estatais surgiram como oportunidades de diversificação setorial (Canuto et al., 1997). As empresas siderúrgicas e de telecomunicações, as rodovias e distribuidoras de energia, as petroquímicas e mineradoras, os bancos estaduais e portos se tornaram ativos valiosos, oportunidades de crescimento com demanda garantida e, em alguns casos, ativos competitivos no mercado externo ou protegidos da concorrência externa.

Muitas empresas estatais eram potencialmente rentáveis. Quando estatais, foram desestruturadas no bojo de sucessivos ajustes fiscais, estavam desatualizadas tecnologicamente, tinham restrição de oferta, apresentavam restrições financeiras devido ao fato de serem públicas e, por isso, não tinham investido em projetos lucrativos. Na década de 1990, para os grupos nacionais, essa foi a única sólida oportunidade de diversificação.

Do ponto de vista dos grupos bem-sucedidos no "jogo da privatização", pode-se notar aspectos positivos. Por exemplo, o controle de algumas empresas estatais modificou substancialmente as estruturas produtivas e organizacionais dos próprios grupos privados. $\mathrm{O}$ acesso a financiamentos, as conexões com mercados externos, a articulação com outros fornecedores e redes de distribuição, a escala dos mercados e a complexidade de algumas atividades criaram novas capacitações privadas. A gestão compartilhada e as alianças corporativas criaram tensões, mas também conexões empresariais importantes, em particular no setor bancário e no mercado de capitais?

Nesse movimento, o BNDES, os fundos de pensão estatais, os fundos de investimentos privados, empresas estrangeiras privadas e estatais surgiram como atores importantes. Os grupos industriais e financeiros que cresceram e se diversificaram na substituição de importações participaram das privatizações, mas foram acompanhados de novos parceiros internos e externos. Essa mescla de atores criou um ambiente mais diverso e complexo para a atuação dos capitais nacionais ${ }^{8}$.

São poucos os casos de governança compartilhada que geraram uma nova identidade corporativa e empresarial, evento mais provável de ocorrer quando se pulveriza o controle acionário. Houve sim a dominância de acionistas majoritários que, quando oportuno, articularam os novos ativos nas antigas estruturas e culturas corporativas. Foram registrados casos de conflitos entre acionistas que levaram a indefinições estratégicas, atraso nos investimentos e mesmo à estagnação. Há casos mais dramáticos com desentendimentos que geraram conflitos que duraram anos, atrasaram investimentos e levaram até mesmo à desarticulação de empresas.

A entrada de capital estrangeiro foi dominante em algumas indústrias e não permitiu a diversificação de capitais nacionais. A entrada de firmas estrangeiras foi determinante para uma maior especialização setorial de alguns grupos nacionais, em particular nos setores intensivos em tecnologia. A pequena escala financeira, a fragilidade tecnológica e a necessidade de maximizar os ganhos com a privatização foram, junto com a massiva entrada de investimento direto estrangeiro, outros determinantes importantes da modesta diversificação do capital nacional no processo de privatização ${ }^{9}$.

\section{ESTRATÉGIAS NA DÉCADA DE 2000 ${ }^{10}$}

Excluindo-se as privatizações, a bem-sucedida política de estabilização inflacionária não criou seguras oportunidades de diversificação e nem garantiu taxas de crescimento significativas. Nesse ambiente, os grupos e grandes empresas nacionais mantiveram uma conservadora coerência corporativa e investiram de forma cautelosa, tanto no mercado interno como no externo.

As diversificações em setores intensivos em tecnologia mantiveram-se praticamente ausentes e quando muito acanhadas, mesmo
7 Vale aqui citar Canuto et al. (1997): "A adaptação ao novo cenário globalizado tem exigido de grupos brasileiros o estabelecimento de parcerias com outros atores-chave, tanto domésticos como estrangeiros. Pode-se esperar que estes novos arranjos trarão 'problemas de agência' que os atuais mecanismos de governança corporativa terão dificuldade de enfrentar. $\mathrm{O}$ tradicional estilo de gestão controlada pelafamília terádeser modificado, sob pena deque os gruposeconômicos nacionais que assim não procederão estagnarão ou desaparecerão. Afinal, parcerias estratégicas entre capitais são incompatíveis com uma proximidade entre patrimônios familiares e dasfirmas absorvedoras de recursos".

8 Ver Lazzarini (2011) para uma descrição das conexões entre esses diversos players no processo de privatização.

9 Ver Sarti e Laplane (2002) sobre os setores preferenciais do investimento diretor estrangeiro na década de 1990.

10 Esse item tem como referência os relatórios de pesquisa da UFMG (2011). 
por parte daqueles grupos que atuavam de forma intensa nesses setores. De fato, pode-se mesmo notar uma intensa desverticalização na manufatura, redução do leque de produtos próprios e uma ampliação da representação de produtores estrangeiros. Nesse processo, uma vantagem importante dos grupos tradables foi a rede de distribuição e o conhecimento sobre as preferências e rendas dos consumidores.

A recuperação econômica pós-2004 criou oportunidades de investimento, mas a crise internacional em 2008 acrescentou incertezas no horizonte de investimento e de diversificação dos grandes capitais. Contudo, a política fiscal expansionista, as políticas pró-investimento e de financiamento domésticas contrabalançaram alguns efeitos negativos, o que criou um cenário dúbio e complexo.

Primeiro, as taxas de crescimento no mercado interno e externo se modificaram significativamente. Progressivamente aumentaram o nível de emprego e a massa salarial. O financiamento às famílias cresceu significativamente e novos consumidores de baixa renda foram incorporados ao mercado. Como resultado, o consumo interno puxou o crescimento da demanda agregada e, assim, o drive exportador que estimulou a diversificação de vários grupos nas duas décadas anteriores deixou de ser dominante. $\mathrm{O}$ mercado interno voltou a ganhar força como determinante dos investimentos e das oportunidades de negócios.

Segundo, a concorrência externa se acirrou em vários setores devido à abertura comercial com valorização cambial, o que desestimulou exportações e colocou em questão a própria capacidade de ofertar ao mercado interno em crescimento. Entretanto, no sentido inverso, a recuperação dos preços das commodities manteve competitivos alguns segmentos tradables, que aumentaram exportações com a crescente demanda asiática. Esses múltiplos e sincrônicos sinais de mercado viabilizaram e restringiram investimentos nos mercados internos e externos, diversamente do que ocorreu quando na presença de políticas voltadas à geração de saldos comerciais.

Terceiro, as taxas de juros domésticas mantiveram-se elevadas, mas o crédito ex- terno se manteve abundante, e financiamentos públicos estimularam investimentos privados. Com a oferta e variedade de crédito, os investimentos deixaram de ter as fortes restrições de financiamento registradas nas décadas anteriores. Contudo, a rentabilidade prospectiva dos projetos se tornou mais complexa, um reflexo não somente da concorrência externa, mas também de diferentes taxas de crescimento da demanda setorial e da intensidade tecnológica da produção.

Quarto, as políticas públicas continuaram dispersas, variadas e respondendo às demandas específicas, muitas delas institucionalmente definidas. Não se pode afirmar que houve uma sistemática e coesa intervenção pública, mas, sim, intervenções públicas que muitas vezes se refletiram em oportunidades localizadas de negócios. Vale registrar que não se notou nas políticas públicas qualquer preferência destacada por capitais nacionais ou mesmo restrições às inversões estrangeiras; para os capitais nacionais, esse é um aspecto importante que diferencia esse período de outros que o precederam.

Esse cenário econômico foi resultado de uma política macroeconômica voltada à manutenção do crescimento com estabilidade inflacionária, mas que forneceu conflitantes sinais para a diversificação dos grupos econômicos nacionais. Oportunidades foram criadas no mercado interno com a recuperação da demanda, mas oportunidades também foram criadas no mercado externo com farta disponibilidade de financiamentos e crescimento do comércio. Os impactos foram também assimétricos quando se observa o mix taxa de câmbio e preços de commodities, pois para alguns tais efeitos se compensaram, mas para outros o resultado foi perverso mesmo para a manutenção da participação no mercado interno.

De fato, nas estratégias de diversificação produtiva e de mercados, só merece destaque a internacionalização produtiva e financeira de alguns grupos industriais e financeiros. Esse destaque se deve mais à "novidade estratégica" do que a sua escala e disseminação, pois poucos grupos se internacionali- 


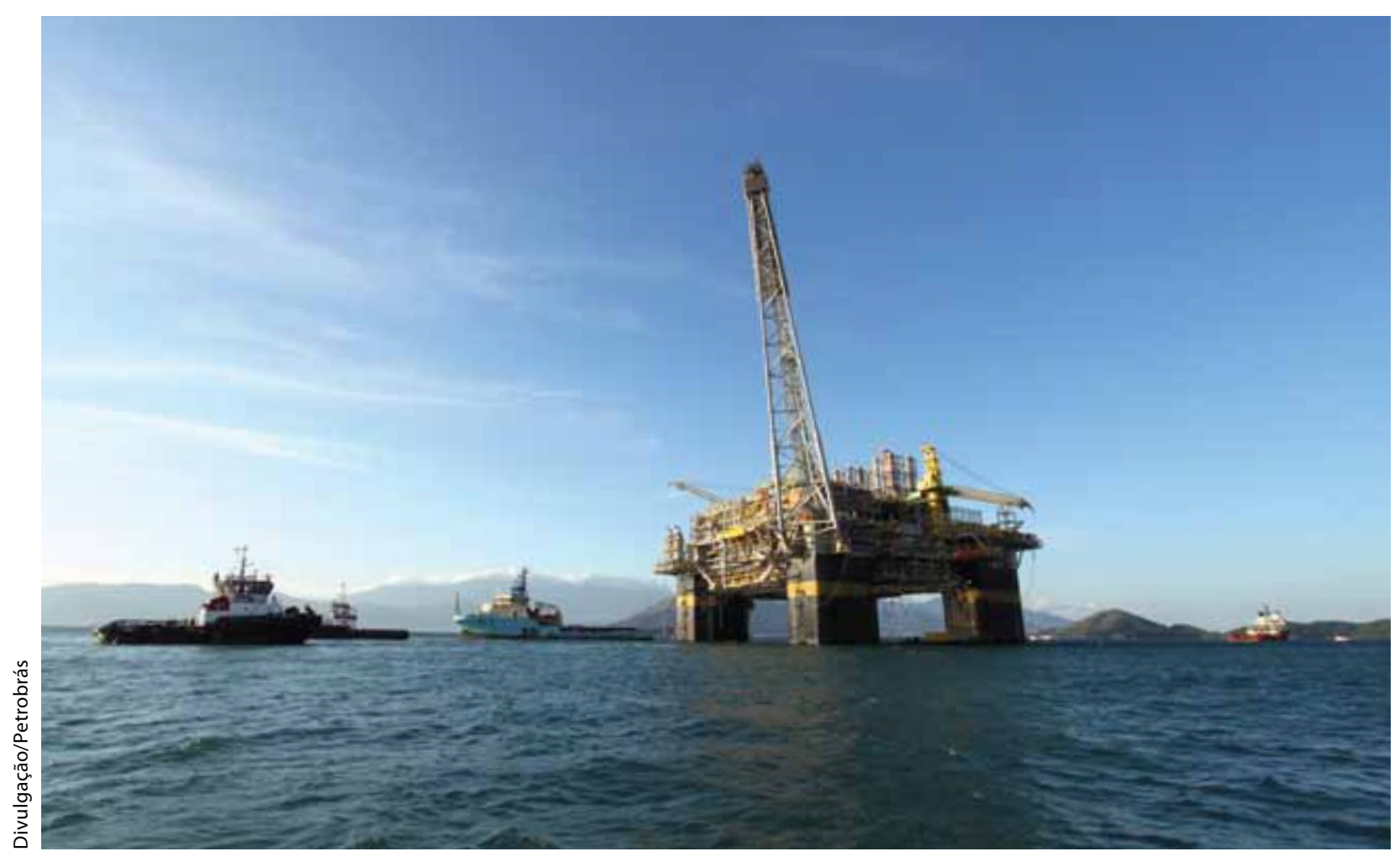

zaram. Após a crise de 2008, não obstante a restrição de crédito externo, a desvalorização de ativos em vários países europeus e nos EUA surgiu como outra oportunidade de negócios, mas poucos grupos nacionais se atreveram a esse movimento de forma mais ofensiva. Alguns grupos se mostraram muito agressivos nesse processo, mas a larga maioria ainda se mostrou pouco propensa a esses investimentos e, quando o fizeram, os maiores e mais competitivos mercados não foram os que atraíram a atenção. De qualquer modo, a internacionalização recente é a mais intensa já registrada (BNDES, 1995; Arbix et al., 2005; FDC, 2010).

Para os grupos estrangeiros a estratégia foi mais simples, convencional e direta: a articulação das subsidiárias na rede de comércio intrafirma permitiu ajustes variados dos produtos em função do perfil de consumidores. Em alguns setores, esse comércio intrafirma minimizou a necessidade de novos investimentos na ampliação de capacidade produtiva e/ou modernização tecnológica, inclusive na reestruturação da sua rede de fornecedores locais. Um resultado é que esses grupos são responsáveis por parte importante do déficit comercial em vários setores industriais.

A participação estrangeira assumiu uma variedade de formas: associação de empresas estrangeiras com nacionais na distribuição, joint-ventures para produção conjunta em linhas de produtos específicas, investimentos minoritários por meio de fundos de investimentos, etc. Nesse movimento do capital estrangeiro, os fundos de investimentos surgiram como importantes players, mas ainda dominam o controle total do capital das filiais por matrizes e uma modesta interação com capitais nacionais.

As oportunidades de investimento no mercado interno foram variadas: da extração de petróleo e construção civil até a educação, a produção de álcool e a indústria naval. Entretanto, somente no período mais recente (pós-2009) alguns grupos passaram a se diversificar seguindo o "rastro da demanda" dos grandes projetos de empresas estatais ou vinculados ao orçamento público federal. Em alguns casos, já se observam até movimentos que poderiam ser classificados de "pouco coerentes" e "oportunistas". Nesse
Plataforma P-56 da Petrobrás 
11 Entendo que para uma estratégia de diversificação schumpeteriana é necessário uma radical intensificação do P\&D empresarial, que ainda está por ser feito no Brasil. As grandes empresas com mais de $\mathrm{R} \$ 800$ milhões de faturamento e/ou mais de 1.000 empregados deveriam sercapazes de formatar algum P\&D in house. Em 2008 temos aproximadamente 1.200 empresas no setor manufatureiro com esse porte, sendo 800 de capital nacional. Dentre essas, apenas 274 têm um departamento estruturado de P\&D (Esteves, 2011).

12 A modesta interação entre universidades/institutos de pesquisas e corporações privadas está dimensionada nos relatórios de avaliação do FNDCT (2010). O estudo mostra que a base científica e tecnológica nacional está relativamente próxima aos padrões mundiais quando comparada ao seu uso efetivo em termos de patenteamento privado. Essa é uma conclusão pessimista, mas é também um sinal das oportunidades tecnológicas latentes no sistema naciona de inovação. crescimento não se notou um papel decisivo das políticas públicas com preferência para latecomers nacionais. Entre as oportunidades detectadas pelas corporações nacionais, com raríssimas e conhecidas exceções, se manteve uma modesta opção por atividades intensivas em tecnologia ${ }^{11}$.

\section{O ANTIGO E O NOVO: CONFLITOS E ARTICULAÇÃO DE INTERESSES}

Ao observar as oportunidades de mercados e tecnológicas, a questão central de uma política pró-diversificação dos grupos e grandes empresas nacionais é como migrar das antigas estruturas e inserções setoriais para outra, tão ou mais rentável. De outro modo: como migrar da riqueza antiga para a riqueza nova?

Como comentado acima, as estratégias de diversificação têm como referência os core business. As oportunidades tecnológicas observadas por um grupo são fortemente localizadas e específicas das suas empresas. Essa coesão dos negócios produz também um conservadorismo empresarial, uma inércia nos negócios. Além desse aspecto, os ativos correntes são as bases da acumulação de capital e as fontes de financiamento à diversificação. Logo, há uma dupla articulação entre riqueza antiga e riqueza nova: primeiro, por meio da coesão corporativa e, segundo, pelo modo como são financiadas as novas inversões.

Nesse contexto a pergunta central é: o que os grupos podem fazer de novo, dados seus ativos, lucros e capacitações? Esse é um cálculo fundamental para entender as imensas dificuldades de uma política que pretende gerar o novo a partir do antigo. Mais do que no caso dos investimentos para o crescimento, os investimentos para diversificação requerem ambientes políticos e econômicos que reduzam radicalmente a incerteza. São necessários múltiplos mecanismos financeiros para canalizar recursos privados, articulações com sistemas setoriais de inovação, associações de capitais para minimizar riscos privados individuais e acelerar o aprendizado e, quando for o caso, uma articulação com instituições públicas que definem as condições e a regulação da concorrência setorial.

Qual a razão para tantos requisitos? Novamente: os núcleos de negócios e as competências corporativas definem quais oportunidades tecnológicas são possíveis de serem exploradas. Romper com esse núcleo requer uma drástica redução das incertezas e rápido aprendizado tecnológico lato sensu. A diversificação requer a constituição de firmas, o controle de uma pluralidade de novas competências organizacionais e tecnológicas e a montagem de uma estrutura própria de inovação. Em alguns casos, é muito provável que sejam criadas novas formas de articulação com firmas nacionais e estrangeiras, além de novas relações cooperativas com instituições de ciência e tecnologia; relações praticamente inexistentes na maioria das corporações privadas ${ }^{12}$.

Dado o risco e complexidade dessa estratégia, é certo que poucos capitais terão escala financeira e ousarão realocar capital dos antigos ativos para os novos ativos. A decisão privada poderá ser apoiada e induzida por políticas e instituições públicas, mas a flexibilidade tanto privada como pública na modelagem de projetos de investimento será fundamental. Não por acaso, políticas públicas e uma variedade de instituições de recorte setorial sempre fizeram parte do rol de requisitos para que tais estratégias de diversificação tomassem curso efetivo.

Um dos pontos centrais da diversificação estará na reorganização das corporações em direção à inovação e à capacitação tecnológica própria. Dificilmente se avançará na diversificação por meio de aquisição de players no mercado nacional, mas já no mercado externo essa estratégia ainda tem possibilidade de prosperar. Mas qualquer que seja a estratégia, mantidos o ambiente pró-crescimento e a abertura econômica, a diversificação dos grandes capitais nacionais passará a depender cada vez mais da construção desses núcleos endógenos de tecnologia, pois eles serão determinantes não somente da diversificação no mercado interno, mas também da internacionalização. 


\section{BIBLIOGRAFIA}

ALCHIAN, A.; DEMSETZ, H. "Production, Information Costs, and Economic Organization", in L. Putterman \& R. Kroszner. The Economic Nature of the Firm. 10th printing. Cambridge University Press, 2008.

AQUINO, C. História Empresarial Vivida. Volumes I, II, III e IV. São Paulo, Gazeta Mercantil, 1987.

AQUINO, C. História Empresarial Vivida. Volume V. São Paulo, Atlas, 1991.

ARBIX, G; Salerno, M. S.; DE NEGRI, J. A. “O Impacto da Internacionalização com Foco na Inovação Tecnológica sobre as Exportações das Firmas Brasileiras", in Dados - Revista de Ciências Sociais. Rio de Janeiro, vol. 48, o 1, 2005, pp. 395-442.

AVALIAÇÃO DO FNDCT. Pesquisa Metodologia de Avaliação dos Resultados de Conjuntos de Projetos Apoiados por Fundos de Ciência, Tecnologia e Inovação. Belo Horizonte, UFMG-MCT/Finep/Ipea, 2010.

BNDES. "Caracterização do Processo de Internacionalização de Grupos Econômicos Privados Brasileiros", BNDES/AP/Depes/Gepes 1. Rio de Janeiro, novembro de 1995 (mimeo.)

CANUTO, O.; RABELO, F. M. \& SILVEIRA, J. M. "Abertura e Grupos Econômicos na Indústria Brasileira", in Revista Paranaense de Desenvolvimento, no 92, set.-dez./1997, pp. 33-52.

CHANDLER, A. D. Jr. Strategy and Structure: Chapters in the History of the Industrial Enterprise. Cambridge, MA, Harvard University Press, 1962.

The Visible Hand: The Managerial Revolution in American Business. Cambridge, MA, Harvard University Press, 1977.

Scale and Scope: The Dynamics of Industrial Capitalism. Cambridge, Mass. and London, Havard U. Press, 1990.

DOSI, G.; TEECE, D. J.; WINTER, S. "Toward a Theory of Corporate Coherence: Preliminary Remarks", in G. Dosi, R. Giannetti, R. \& P. A. Toninelli. Techology and Enterprise in a Historical Perspective. Oxford, Clarendon Press, 1992.

DOSI, G.; FAILLO, M.; MARENGO, L. “Organizational Capabilities, Patterns of Knowledge Accumulation and Governance Structures in Business Firms - An Introduction", in Working Paper Series 2003/11, July 2003. Italy, Laboratory of Economics and Management Sant'Anna School of Advanced Studies.

ESTEVES, L. A. “Empresas Líderes na Indústria Brasileira: Panorama 2008”. Relatório de pesquisa da UFMG, 2011.

FDC. Ranking das Transnacionais Brasileiras. Belo Horizonte, Fundação Dom Cabral, 2010.

FOSS, N. "The Resource-based Perspective: an Assessment and Diagnosis of Problems", in Scandinavian Journal of Management. vol. 14, no 3, 1997, pp. 133-49.

FOSS, N. "Edith Penrose and the Penrosians - or, Why There Is Still so Much to Learn from The Theory of the Growth of the Firm", in Department of Industrial Economics and Strategy (Working Paper). Copenhagen Business School, Denmark, 1998.

HART, O.; MOORE, J. "Property Rights and the Nature of the Firm", in Journal of Political Economy. 98(6), December 1990, pp. 1.119-58.

HOLMSTROM, B.; MILGROM, P. "The Firm as an Incentive System”, in Journal of Law, Economics \& Organization, v. 15, no 1, 1994.

HOLMSTROM, B.; MILGROM, P.; TIROLE, J. "The Theory of the Firm", in Handbook of Industrial Organization. Volume I. North-Holland, Elsevier Science Publisher, 1989. 
LAZZARINI, S. G. Capitalismo de Laços: os Donos do Brasil e Suas Conexões. São Paulo, Campus, 2011.

PENROSE, E. Teoria do Crescimento da Firma. Campinas, Editora Unicamp, 1959.

PRAHALAD, C. J.; HAMEL, G. "The Core Competence of the Corporation", in Harvard Business Review, 1990.

QUEIROZ, M. V. Grupos Econômicos e o Modelo Brasileiro. Tese de doutourado. São Paulo, Dep. Ciências Sociais da Faculdade de Filosofia, Letras e Ciências Humanas da USP, 1972.

REISS, G. D. Development of Brazilian Industrial Enterprise: a Historical Perspective. Tese de doutorado. Berkeley, Universidade da Califórnia, 1980.

. "O Crescimento da Empresa Industrial na Economia Cafeeira", in Revista de Economia Política. vol. 3, no 2. São Paulo, 1983.

RUIZ, R. M. Estratégia Empresarial e Reestruturação Industrial (1980-1992): um Estudo de Grupos Econômicos Selecionados. Dissertação de mestrado apresentada ao IE/ Unicamp. Campinas, Unicamp, 1994.

RUMELT, R. P. "Toward a Strategic Theory of the Firm", in N. Foss. Resources, Firms, and Strategies - A Reader in the Resource-Based Perspective. England, Oxford Press, 1997.

SAES, F. A. M. "A Controvérsia sobre a Industrialização na Primeira República", in Estudos Avançados, vol. 3, no 7. São Paulo, IEA-USP, 1989.

SARTI, F.; LAPLANE, M. "O Investimento Direto Estrangeiro e a Internacionalização da Economia Brasileira nos Anos 1990", in Economia e Sociedade. Campinas, v. 11, n. 1 (18), jan.-jun./2002, pp. 63-94.

TEECE, D. J. "The Dynamics of Industrial Capitalism: perspectives on Alfred Chandler's 'Scale and Scope',' in The Journal of Economic Literature. vol. XXXi, March 1993, n. 1. . "Firm Organization, Industrial Structure, and Technological Innovation", in Journal of Economic Behavior \& Organization. Vol. 31, 1996, pp. 193-224.

TEECE, D. J.; RUMELT, R. P., DOSI, G.; WINTER, S. G. “Understanding Corporate Coherence: Theory and Evidence", in Journal of Economic Behavior and Organization. 23, 1994, pp. 1-30.

UFMG. "Diversificação e Consolidação dos Grupos Econômicos Privados Nacionais: Estrutura Corporativa, Inovação Tecnológica e Políticas de Indução". Coordenador: professor Gustavo Brito Cedeplar/CGEE/Fundep-UFMG, 2011.

UNICAMP. Relatórios do Projeto "Grupos Econômicos na Indústria Brasileira e a Política Econômica: Estrutura, Estratégias e Desafios". Fundap, Fecamp, Unicamp e IE/NEIT. Campinas, São Paulo, 1996.

WILLIAMSON, O. E. "Transaction Cost Economics", in Handbook of Industrial Organization. Volume I, Edited by R. Schmalensee and R. D. Willing, Elsevier Science Publishers, 1989. 